The arguments of the second chapter, that axiomatic field theory is too restrictive, appear to be reasonably convincing and lead to the suggestion of an indefinite motric. On the other hand, the attempt to show that tho unified field theory is somewhat simpler than $S$-matrix theory is not a success. In view of the many difficulties with the idea of a local field, which Heisenberg very efficiently demonstrates, one expects to find more powerful arguments for retaining this idea. The basic assumptions of the theory are given in the third chapter. Compared with the rather majestically phrased (if slightly obscure) basic postulates of $S$-matrix theory or axiomatic field theory, it is hard to have to start with an equation which appears to be one of many possibilities and suggests that it was chosen merely to fit particular experimental facts rather than derived from anything more basic. The situation becomes even worse, however, in section 3.3 , where it appears that the commutation relations still have to be guessed rather than derived, and one is left somewhat uncortain here as to what is being assumed and what is proved.

This book has an enormous scope-unified field theory really does attempt to comprehend everything from low energy weak interactions to high energy limits of strong interactions in terms of one equation. Many tentative suggestions are given in the book with regard to how the wide variety of phenomena might occur in the theory, but, as Heisenberg admits, the theory is in most cases in its infancy. Whether in general terms the ideas are genuinely in their infancy or in their old age is questionable. Notions of a degenerate vacuum and indefinite metric are new and liberating-perhaps thoy will opon up the explanation of the whole range of elementary particle phenomena. Notions of local field theory, however, are old and may well be too restrictive, in which case they will no doubt die. Because this book exists-and is well worth the $47 \mathrm{~s}$. it costs-I am relieved of the task of forming a judgment.

E. J. Squires

\section{INVISCID FLOW}

\section{The Theory of Jets in an Ideal Fluid}

By M. I. Gurevich. Translated by R. E. Hunt. Translation edited by E. E. Jones and G. Power. (International Series of Monographs in Pure and Applied Mathematics, Vol. 93.) Pp. viii +412. (Oxford, London and New York: Pergamon Press, Ltd., 1966.) 100s.

'THis book was originally published in Moscow in 1961 and contains a systematic treatment of the theory of jets in inviscid fluids. It has already been widely acclaimed as an important major work and will be familiar to many English language readers through an earlier translation published by the Academic Press. A sound knowledge of the fundamentals of hydromechanics and complex variable theory is assumed at the start and the genoral level of the work is postgraduate.

The book commences with a review of the classical ideal flow theory and describes the methods of Kirchoff, Joukovskii (Zhukovsky) and Chaplygin. The second chapter covers flow from vessels or channels with rectilinear walls and is followed by a chapter on infinite flow past a polygonal body. Flow past curvilinear bodies includes sections on Levi-Civita's method, Villat's equation and Sedov's general method for the problem of flow past several curvilinear arcs. After an introduction to the phenomenon of cavitation, the next two chapters eover flow at low cavitation numbers past bodies and a varicty of flows of limited jots, including flow around a symmetric and asymmotric wedgo and both cavitating and noncavitating cascade flow. The seventh chaptor deals with planing surfaces and submerged hydrofoils, and the eighth eovers some miscellaneous free-jet phonomonn including armour piercing jets. The final chapters cover unsteady jet flows, compressible fluids, axisymmetric jet flows and jet flows in a heavy fluid and the effects of surface tension. The English text is easy to follow although some of the phrases are clearly from a literal translation and could perhaps have been expressed colloquially.

The 259 references contain more than a hundred Russian titles, but it would have been useful to have more details of recont English language translations where these are available. Similarly, further reference to work published since 1960 would have been desirable.

Professor Gurevich's excellent work is a valuable addition to the literature and it has alrcady taken its place as a standard reference supplementing the earlier work on Jets, Wakes and Cavities, by G. Birkoff and E. H. Zarantonello (Academic Press, 1957).

J. C. McVrigh

\section{TESTING FOR PERFORMANCE}

\section{Testing of Polymers}

Vol. 2. Edited by John V. Schmitz. Pp. xiii +421 . (New York and London: Interscience Publishers, a Division of John Wiley and Sons, 1966.) $152 s$.

THE publishers of this volume claim that it "gives a critical survoy of testing methods . . . of evaluating individual properties . . . for end-use performance". Using the assertion as a basis for judgment, the work eannot be rated a success.

The eleven chapters, all by different authors, and varying in length from sixteen to fifty-four pages, range from a straightforward description of wear testing machines to a condensed résumé of the physics of polymer structure. Fears are roused by the first sentence of the first chapter: "The measuremont of the stress relaxation of a high polymer is one of the simpler visco-elastic measuremonts". The measurement may be extremely simple, but interpretation and evaluation are completely different matters. With some exceptions the same fault occurs continually throughout the volume; idealized principles aro mentioned and test methods described, but no adequate critical discussion is given of the relevance of the tests to tho performance of a finished product.

In the chapter on tests for hardness and wear of plastics the conclusions, which occupy only ten lines, state merely that "test data are valuable in ranking plastics ... if the conditions of use are properly definod". The purpose of the article ought to have been to aid proper definition of these necessary conditions. This chapter might well be read as a warning by intending authors. Too much apparatus is deseribed inadequately; many of the photographic illustrations do little more than give an impression of the size of equipment; and in a graph purporting to show the effect of moisture on hardness of PMMA the comparison is made between a wet sample at $25^{\circ} \mathrm{C}$ and a dry one at $60^{\circ} \mathrm{C}$, despite an accompanying statement emphasizing that hardness is very temporaturo sensitivo.

The most useful article is probably that on processing of numerical test data. It gives a clear introduction to the design and evaluation of experiments; although the statistical mothods are general, examples are given from the polymer field. This section of the chapter might well have been expanded by starting at a slightly less elementary lovel, and also by omitting irrelevant data.

Several chapters give competent reviews of test methods, but only rarely is the review a critical one. Lists, and sometimes descriptions, of relevant standard methods are a useful feature-which would have been even more useful if an identical procedure had been followed in cach chapter. Such systematization would, however, have conflicted with the editor's decision that "authors ... follow individual preferences in style and organization". A change in this docision might also have prevented phrases such as "To pursue the question of induced radioactivity a bit 